\title{
Copper-Coated Graphene Nanoplatelets-Reinforced Al-Si Alloy Matrix Composites Fabricated by Stir Casting Method
}

\author{
Xiaoqi Han ${ }^{1} \cdot$ Lizhuang Yang $^{1}$ - Naiqin Zhao ${ }^{1,3,4}$. Chunnian $\mathrm{He}^{1,2,3,4}$ \\ Received: 21 March 2020 / Revised: 24 May 2020 / Accepted: 6 June 2020 / Published online: 15 August 2020 \\ (c) The Chinese Society for Metals (CSM) and Springer-Verlag GmbH Germany, part of Springer Nature 2020
}

\begin{abstract}
In this study, Cu nanoparticles-coated graphene nanoplatelets (Cu-NPs@GNPs) were synthesized by a simple in situ method with the assistance of $\mathrm{NaCl}$ templates and used for reinforcing $\mathrm{Al}-10 \mathrm{Si}$ composites through stir casting process. The experimental results showed that the coating of $\mathrm{Cu}-\mathrm{NPs}$ on the GNPs could compromise the density mismatch between GNPs and metal matrix and effectively hinder the float of GNPs during stirring. The reaction of $\mathrm{Cu}$-NPs and $\mathrm{Al}$ matrix could protect the structural integrity of GNPs as well as improve the interfacial wettability between GNPs and the matrix, thus promoting the uniform dispersion of GNPs in the composites. As a result, the as-prepared 0.5 wt\% Cu-NPs@ GNPs/Al-10Si composite exhibited a tensile strength of $251 \mathrm{MPa}$ ( $45 \%$ higher than the Al-10Si) with a total elongation of $15 \%$. The strengthening effects were mainly attributed to the following three reasons: Firstly, the Cu-NPs coating improved the interfacial bonding between GNPs and $\mathrm{Al}$ matrix which promoted the load transfer from the matrix to the GNPs. Secondly, the nanoscale $\mathrm{Al}_{2} \mathrm{Cu}$ formed by the reaction of $\mathrm{Cu}-\mathrm{NPs}$ and $\mathrm{Al}$ matrix played a role in precipitation strengthening. Thirdly, GNPs refined the silicon phases and improved the monolithic performances of the composites.
\end{abstract}

Keywords Al-Si alloy $\cdot$ Graphene $\cdot$ Stir casting $\cdot$ Wettability $\cdot$ Si phase refinement

\section{Introduction}

Available online at http://link.springer.com/journal/40195.

Electronic supplementary material The online version of this article (https://doi.org/10.1007/s40195-020-01112-1) contains supplementary material, which is available to authorized users.

Lizhuang Yang

yanglz@tju.edu.cn

$\bowtie$ Chunnian $\mathrm{He}$

cnhe08@tju.edu.cn

1 School of Materials Science and Engineering and Tianjin Key Laboratory of Composite and Functional Materials, Tianjin University, Tianjin 300072, China

2 Joint School of National University of Singapore and Tianjin University, International Campus of Tianjin University, Binhai New City, Fuzhou 350207, China

3 Collaborative Innovation Center of Chemical Science and Engineering (Tianjin), Tianjin 300072, China

4 Key Laboratory of Advanced Ceramics and Machining Technology, Ministry of Education, Tianjin University, Tianjin 300072, China

Aluminum matrix composites (AMCs) have a great application prospects in industrial field and receive an increasing attention in academic research due to their marvelous properties including high strength, low density, good corrosion resistance, suitable process ability as well as fair price and abundant resources of matrix materials [1,2].

Graphene is a kind of two-dimensional nanomaterial formed by a single layer of carbon atoms strongly bonded together with $s p^{2}$ hybrid orbital. Owing to its excellent properties including high intrinsic strength (130 GPa) [3], high Young's modulus (1 TPa) [3], large specific surface area $\left(2630 \mathrm{~m}^{2} \mathrm{~g}^{-1}\right)$ [4], high thermal conductivity $\left(5000 \mathrm{~W} \mathrm{~m}^{-1} \mathrm{~K}^{-1}\right)$ [5], superior mobility of charge carriers $\left(200,000 \mathrm{~cm}^{2} \mathrm{~V}^{-1} \mathrm{~s}^{-1}\right)$ [6] and low density $\left(2.2 \mathrm{~g} \mathrm{~cm}^{-3}\right)$, graphene is considered as an effective reinforcement for aluminum matrix composites. Attributed to the larger specific surface area which provided more interfaces with sufficient load transfer, few-layered GNs show a higher strengthening efficiency than multi-walled carbon nanotubes for reinforcing AMCs [7]. 
In order to take full advantages of the extraordinary mechanical properties of graphene, it is necessary to achieve homogenous dispersion and strong interfacial bonding of them in the composites. Ball milling has been proven to be an effective method and widely used method to uniformly disperse graphene in metal matrix by high shear force [8-11]. During the shift-speed ball milling process (SSBM), low-speed ball milling (LSBM) provides the mild shear force for the reinforcement uniformly dispersed on the surface of $\mathrm{Al}$ powders and the following high-speed ball milling (HSBM) causes the reinforcement to be embedded in deformed $\mathrm{Al}$ powders [12]. Ball milling time is also an important factor that affects the dispersion efficiency. Previous researches revealed that sufficient ball milling time not only enabled graphene to disperse well in the Al powders but also helped to reduce the number of graphene layers [8, 10]. However, excessive ball milling energy would damage the structural integrality of graphene and promote it reacted with $\mathrm{Al}$ matrix during sintering process to form $\mathrm{Al}_{4} \mathrm{C}_{3}$ brittle phase which will deteriorate the strength and toughness of the composites. In short, the ball milling technique with reasonable parameters can effectively uniformly disperse graphene in the metal matrix to achieve the mass production process of composites.

In terms of composites forming process, previous studies utilized solid state process such as hot pressing [13], spark plasma sintering [14], friction stir process [15] and semi-solid process like pressure infiltration method [16] to fabricate graphene-reinforced aluminum matrix composites (GRAMCs). Nevertheless, issues such as complicated preparation process, long manufacturing period, strict requirements on equipment and high cost are still unavoidable by the above solid-state methods. Compared with that, liquid process with the advantages of high yield, low cost and simple operation has the potential to become a breakthrough to achieve the mass production of GRAMCs [17, 18]. Unfortunately, the existing density mismatch and poor wettability between GNs and molten aluminum make the GNs always tends to float in the molten Al matrix, thus the utilization of liquid process to fabricate GRAMCs is still a challenge. Moreover, the surface tension misfit caused poor wettability between graphene and $\mathrm{Al}$ matrix makes it difficult to achieve an effective interfacial bonding between them, in which may result in a poor strengthening efficiency and poor elongation of the composites. Therefore, it is surely difficult to ideally introduce graphene into molten $\mathrm{Al}$ matrix directly. In this regard, some researchers tried to pre-disperse the graphene into $\mathrm{Al}$ powders by ball milling, and then added those mixed composites powders into molten aluminum during stir casting process for preparing GRAMCs. For instance, Alipour et al. [19] investigated GNPs/AA7068 composite by a combination of powder metallurgy and stir casting with ultrasonic waves, which improved the tensile strength from 495 to $615 \mathrm{MPa}$ after T6 heat treatment with $0.5 \mathrm{wt} \%$ GNPs addition. Li et al. [20] introduced $0.2 \mathrm{wt} \%$ GNPs into pure aluminum matrix by stir casting process and improved the tensile strength from 114 to $156 \mathrm{MPa}$ with a dropped elongation from 11 to $4 \%$. In both studies, pre-ball milling was applied to embed graphene into aluminum powder and hinder the upward floating of graphene in melting matrix. Although this method is helpful to introduce graphene into the matrix, the problem of it in the matrix is still not well solved, leading to the unavoidable defects and deteriorative elongation.

In the previous work, our group successfully synthesized a mass of $\mathrm{Ni}$ nanoparticles-coated graphene [21] and $\mathrm{Cu}-$ NPs-coated graphene [22] by a simple in situ catalytic synthesis method with the assistance of $\mathrm{NaCl}$ template. The coated GNPs were utilized to reinforce $6061 \mathrm{Al}$ alloy and pure $\mathrm{Al}$ matrix composites, which achieved stronger interfacial bonding between the reinforcement and $\mathrm{Al}$ matrix by forming intermetallic compounds $\mathrm{Al}_{3} \mathrm{Ni}$ and $\mathrm{Al}_{2} \mathrm{Cu}$ on the interface, respectively. In this work, the in situ synthesized copper nanoparticles-coated graphene nanoplatelets $(\mathrm{Cu}-\mathrm{NPs} @ \mathrm{GNPs})$ were applied to reinforce the Al-10Si alloy matrix composites by a combination of ball milling and subsequent stir casting method. The coating of $\mathrm{Cu}-\mathrm{NPs}$ cannot only compromise the density misfit between GNPs and matrix which hinder the upward floating of GNPs in molten Al-Si alloy, but also remain the integrality of GNPs and promote the interfacial bonding between the GNPs and the matrix by forming $\mathrm{Al}_{2} \mathrm{Cu}$ at the interface. In this way, Cu-NPs@GNPs-reinforced Al-Si alloy matrix composites with high strength and moderate ductility could be obtained on a large scale. Several groups of comparative experiments were synchronously carried out to investigate the effect of $\mathrm{Cu}-\mathrm{NPs}$ and GNPs on the microstructure and mechanical properties of the composites.

\section{Experimental}

\subsection{Preparation of Cu-NPs@GNPs}

Figure 1 shows the typical preparation process of the $\mathrm{Cu}-\mathrm{NPs} @ \mathrm{GNPs} / \mathrm{Al}-10 \mathrm{Si}$ composites. Firstly, $4.53 \mathrm{~g} \mathrm{Cu}$ $\left(\mathrm{NO}_{3}\right)_{2} \cdot 3 \mathrm{H}_{2} \mathrm{O}$ (copper source), $1.87 \mathrm{~g} \mathrm{C}_{6} \mathrm{H}_{12} \mathrm{O}_{6}$ (carbon source) and $54.88 \mathrm{~g} \mathrm{NaCl}$ (salt template) were dissolved into $260 \mathrm{ml}$ deionized water and magnetic-stirred for $2 \mathrm{~h}$ to form uniform precursor solution, and it was spraydried into micrometer-sized spherical powders by forming large quantities of $\mathrm{NaCl} @ \mathrm{C}_{6} \mathrm{H}_{12} \mathrm{O}_{6}-\mathrm{Cu}\left(\mathrm{NO}_{3}\right)_{2}$ cubes using spray pyrolysis method. Then, the precursor powders were calcined in a tube furnace at $750{ }^{\circ} \mathrm{C}$ under $\mathrm{H}_{2}$ atmosphere for $2 \mathrm{~h}$. The $\mathrm{NaCl}$ template in the calcined powders were removed by deionized water and dried in 


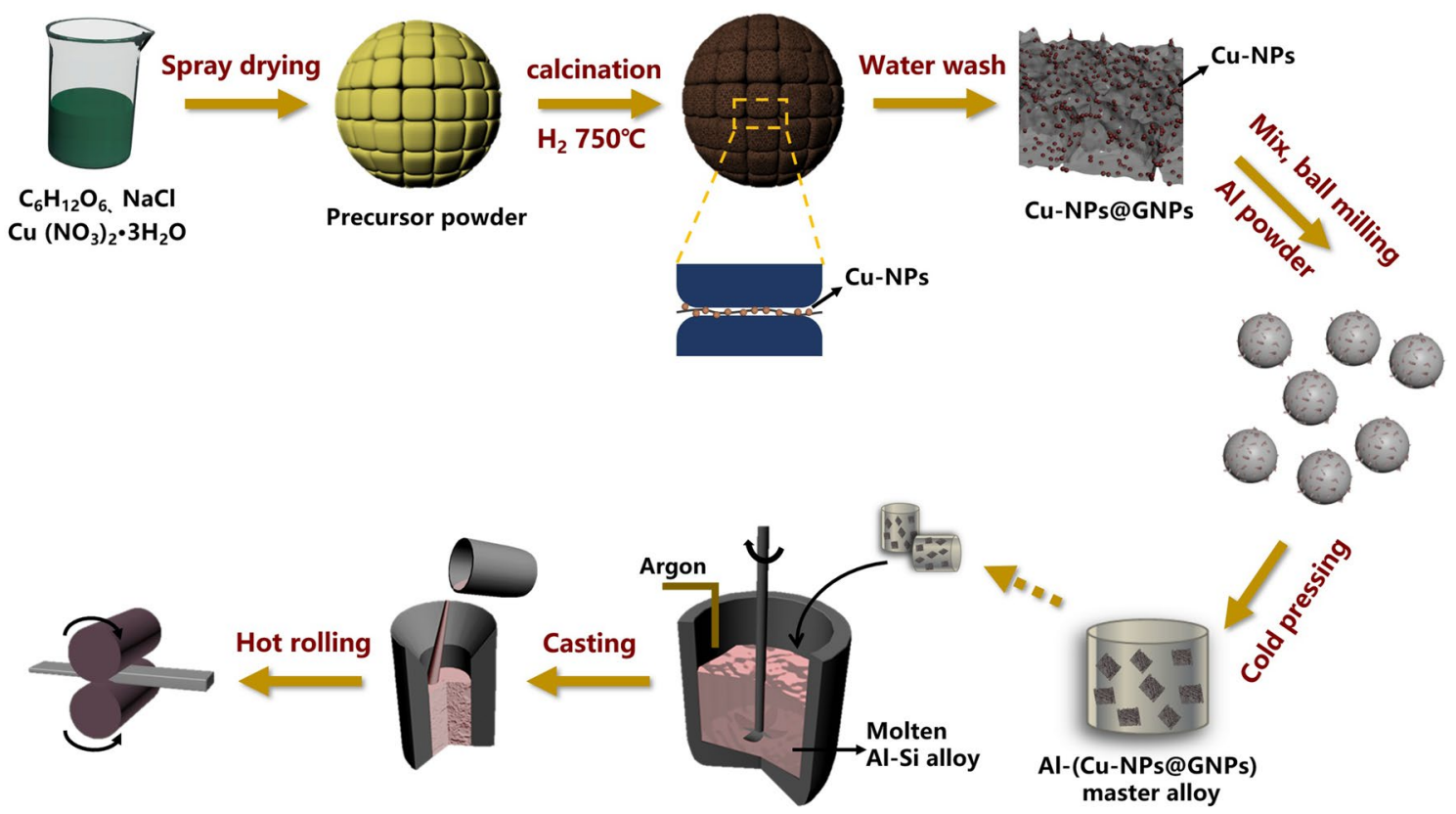

Fig. 1 Schematic illustration of the in situ catalytic synthesis and stir casting-hot rolling process for the fabrication of Cu-NPs@GNPs/Al-10Si composites

an oven at $80{ }^{\circ} \mathrm{C}$ for $4 \mathrm{~h}$. Finally, dried powders were placed in a tube furnace at $400{ }^{\circ} \mathrm{C}$ for 90 min under $\mathrm{H}_{2}$ atmosphere to get clean Cu-NPs@GNPs.

As a contrast of the aforementioned one-step in situ synthesized Cu-NPs@GNPs, raw GNPs were externally coated with $\mathrm{Cu}$-NPs by electroless copper plating method, which was named as "ex situ Cu-NPs/GNPs". In addition, pure GNPs and copper nanoparticles (Cu-NPs) were prepared separately. The synthetic methods were shown in supporting information.

\subsection{Fabrication of the Cu-NPs@GNPs/AI Powders and AI-(Cu-NPs@GNPs) Master Alloy}

Different contents $(0,1.5,2.5$, and 5 wt $\%)$ of Cu-NPs@ GNPs and Al powders were mixed via planetary SSBM process with a speed of $180 \mathrm{rpm}$ for $2 \mathrm{~h}$ (LSBM) at first and following $360 \mathrm{rpm}$ for $1.5 \mathrm{~h}$ (HSBM), which was carried out using a planetary ball mill in the stainless-steel jars under argon atmosphere with a ball-to-powder ratio of $10: 1$, and $0.3 \mathrm{wt} \%$ stearic acid was added as process control agent. Then, the uniform mixed composite powders were cold pressed into cylinders of $20 \mathrm{~mm}$ in diameter [named as $\mathrm{Al}-(\mathrm{Cu}-\mathrm{NPs} @ \mathrm{GNPs})$ master alloy] under the pressure of $600 \mathrm{MPa}$ for $1 \mathrm{~min}$.

\subsection{Fabrication of the Cu-NPs@GNPs/AI-10Si Composites}

Al-10Si alloy (strontium modified) was elected as the matrix. Firstly, $\mathrm{Al}-12.5 \mathrm{Si}$ alloy melt was prepared by using pure $\mathrm{Al}$ ingots and $\mathrm{Al}-30 \mathrm{Si}$ master alloy ingots in resistance furnace under $750{ }^{\circ} \mathrm{C}$. Then, the encased Al- $(\mathrm{Cu}-\mathrm{NPs} @$ GNPs) master alloy, with aluminum foil was pressed into Al-12.5Si melt from top by bell jar. Strontium (0.02 wt\%) was added into the molten Al-Si alloy as the modifier. As soon as the added Al-(Cu-NPs@GNPs) master alloy melted, the three-blade stirrer (blade angle $45^{\circ}$ ) was immersed vertically into the melt, with a depth of about $2 / 3$ of the melt height. The speed of stirring was set as $200 \mathrm{rpm}$ for $1 \mathrm{~min}$ and $120 \mathrm{rpm}$ for $20 \mathrm{~min}$, which was carried out under argon protection. The mass ratio of Al-(Cu-NPs@GNPs) master alloy and $\mathrm{Al}-12.5 \mathrm{Si}$ melt was 1:4. After the stirring process, argon was injected into the liquid aluminum alloy for $30 \mathrm{~s}$ to remove gas and inclusions from the melt. The flow of argon gas was controlled to the extent that the melt appeared to fluctuate but did not spatter. The molten alloy was then immediately poured into the preheated stainless-steel mold $\left(250{ }^{\circ} \mathrm{C}\right)$. Finally, the cast samples were homogenized at $500{ }^{\circ} \mathrm{C}$ for $5 \mathrm{~h}$ in a chamber electric furnace. In order to avoid introducing impurity metal elements into the melt, the stainless-steel tools such as stirrer, the spoon for removing 
slag, bell jar, pliers for holding the crucible, tube used to inject argon gas inside the melt were all coated with zinc oxide.

Multi-pass hot rolling process was used to treat the cast composites. The specimens $(12 \mathrm{~mm} \times 35 \mathrm{~mm} \times 5 \mathrm{~mm})$ cut from cast samples were heated up to $500{ }^{\circ} \mathrm{C}$ for $1 \mathrm{~min}$, and then hot-rolled rapidly with the reduction of $0.2 \mathrm{~mm}$. This pass was repeated several times until the specimen was totally reduced by $70 \%$. The as-prepared composites with different reinforcement contents were named as $x(\mathrm{Cu}-\mathrm{NPs} @$ GNPs)/Al-10Si composites ( $x=0,0.3,0.5,1.0 \mathrm{wt} \%)$.

As contrast group, $0.3-0.5 \mathrm{wt} \%$ (Cu-NPs)/Al-10Si composites, $0.5 \mathrm{wt} \%$ (ex situ Cu-NPs/GNPs)/Al-10Si composites, $0.5 \mathrm{wt} \%(\mathrm{Cu}-\mathrm{NPs}+\mathrm{GNPs}) / \mathrm{Al}-10 \mathrm{Si}$ composites were also prepared by the same methods. "Cu-NPs + GNPs" means that $\mathrm{Cu}-\mathrm{NPs}$ are not coated on the surface of GNPs, but directly mixed with GNPs and Al powders by ball milling dispersion (using the same parameter mentioned in Sect. 2.2).

\subsection{Characterization}

Field emission scanning electron microscopy (SEM, Hitachi S4800) and high-resolution transmission electron microscopy (TEM, JEM-2100F) were utilized to characterize the microstructure of Cu-NPs@GNPs and composites. Raman spectroscopy (Renishaw, $532 \mathrm{~nm} \mathrm{Ar}^{+}$laser) was used to analyze the quality of Cu-NPs@ GNPs. Thermogravimetric analysis (TGA, Netzsch STA449f3) and differential thermal analysis (DTA) was used to detect the content of Cu or GNPs in the Cu-NPs@GNPs composite powders. X-ray diffraction (XRD, Bruker D8 Advanced) was conducted by using a Rigaku D/max diffractometer with $\mathrm{Cu} K \alpha$ radiation at a wavelength of $1.5406 \AA$ for phase analysis. The specimens for SEM investigations were prepared by mechanical grinding and electrolytic polishing by using the $10 \mathrm{vol} \%$ perchloric acid-alcohol solution. The specimens for TEM analysis were prepared by mechanical polishing to produce a foil of $30 \mu \mathrm{m}$ thickness, followed by ion beam thinning. For tensile tests, dog-bone-shaped specimens $(30 \mathrm{~mm} \times 6 \mathrm{~mm} \times 1.5 \mathrm{~mm})$ were cut from the hot-rolled samples in rolling direction (RD). Tensile tests were conducted on a CSS-44100 universal testing machine with a constant crosshead speed of $0.5 \mathrm{~mm} \mathrm{~min}{ }^{-1}$ at room temperature.

\section{Results}

\subsection{Characterization of Cu-NPs@GNPs}

In order to efficiently prepare a large quantity of high-quality Cu-NPs@GNPs and match the yield requirement for the stir casting method, we used a combination of industrial spray drying method and space-confined catalysis effect [23]. The structure of the micrometer-sized spheres prepared by the spray drying method is shown in Fig. 2a. In this structure, the surface of $\mathrm{NaCl}$ crystals is uniformly coated with the mixture of $\mathrm{C}_{6} \mathrm{H}_{12} \mathrm{O}_{6}-\mathrm{Cu}\left(\mathrm{NO}_{3}\right)_{2}$, which combines together to form the self-assembled spheres and act as the templates. During the high temperature calcination process under hydrogen atmosphere, the cramped space between $\mathrm{NaCl}$ templates limits the growth of $\mathrm{Cu}$ particles and results in keeping their nanoscale. The $\mathrm{Cu}$ nanoparticles play a catalytic role during the carbonization process of $\mathrm{C}_{6} \mathrm{H}_{12} \mathrm{O}_{6}$ thereby the $\mathrm{Cu}$ coating and GNPs catalyzed synthesis are achieved in one-step in situ catalytic process. Figure $2 b$, $c$ shows final SEM images of the product after removing $\mathrm{NaCl}$ templates. Figure $2 \mathrm{~b}$ shows that thin graphene walls interconnect together in a sub-micron frame structure, corresponding to the shape of the $\mathrm{NaCl}$ templates in Fig. 2a. The high-resolution SEM image of Cu-NPs@GNPs in Fig. 2c demonstrates that $\mathrm{Cu}$-NPs are homogenously and closely distributed on the GNPs with mean size of about $50 \mathrm{~nm}$. Figure 2d-f presents the TEM images of Cu-NPs@GNPs microstructure. As shown in Fig. 2d, Cu-NPs are still tightly anchored on the surface of GNPs after ultrasonic treatment of $30 \mathrm{~min}$ in ethanol, indicating that the bonding between $\mathrm{Cu}-\mathrm{NPs}$ and GNPs is very strong. Figure $2 \mathrm{e}$ reveals that the GNPs are well graphitized with a thickness of about $5 \mathrm{~nm}$. Figure $2 \mathrm{f}$ is the high-resolution TEM image of a nanoparticle anchored on the surface of GNPs, which shows (111) plane of it with $0.21 \mathrm{~nm}$ lattice space.

XRD is utilized to detect the phase composition of the nanoparticles coated on the GNPs and the result is displayed in Fig. 3a. Four sharp diffraction peaks are presented in the XRD pattern and their $2 \theta$ values of $43.297^{\circ}, 50.433^{\circ}$, $74.13^{\circ}, 89.931^{\circ}$ correspond to the (111) (200) (220) (311) crystalline planes of metallic $\mathrm{Cu}$ phase, respectively, which demonstrates that the spherical nanoparticles decorated on the GNPs (Fig. 2) are pure $\mathrm{Cu}$.

Raman spectroscopy is used to characterize the crystallinity of Cu-NPs@GNPs and pure GNPs, the results of which are displayed in Fig. 3b. In general, graphene materials present two characteristic bands in the Raman spectra: $\mathrm{D}$ band at about $1350 \mathrm{~cm}^{-1}$ and $\mathrm{G}$ band at about $1601 \mathrm{~cm}^{-1}$ [24]. G band is associated with the in-plane vibration of $s p^{2}$ carbon atoms in graphene and reflects the degree of crystallization of the carbon layer, while $\mathrm{D}$ band is related to edge defects and reflects the disorder as well as defect between the graphite layers. The intensity ratio of D peak to $\mathrm{G}$ peak $\left(I_{\mathrm{D}} / I_{\mathrm{G}}\right)$ is generally used to measure degree of defects of the graphene material $[25,26]$. As shown in Fig. 3b, the values of $I_{\mathrm{D}} / I_{\mathrm{G}}$ of Cu-NPs@GNPs and GNPs are 0.88 and 0.89, respectively, which confirm the relatively high crystallinity of these two graphene materials. TGA together with DTA were used to detect the content of $\mathrm{Cu}$ and GNPs in Cu-NPs@GNPs by 

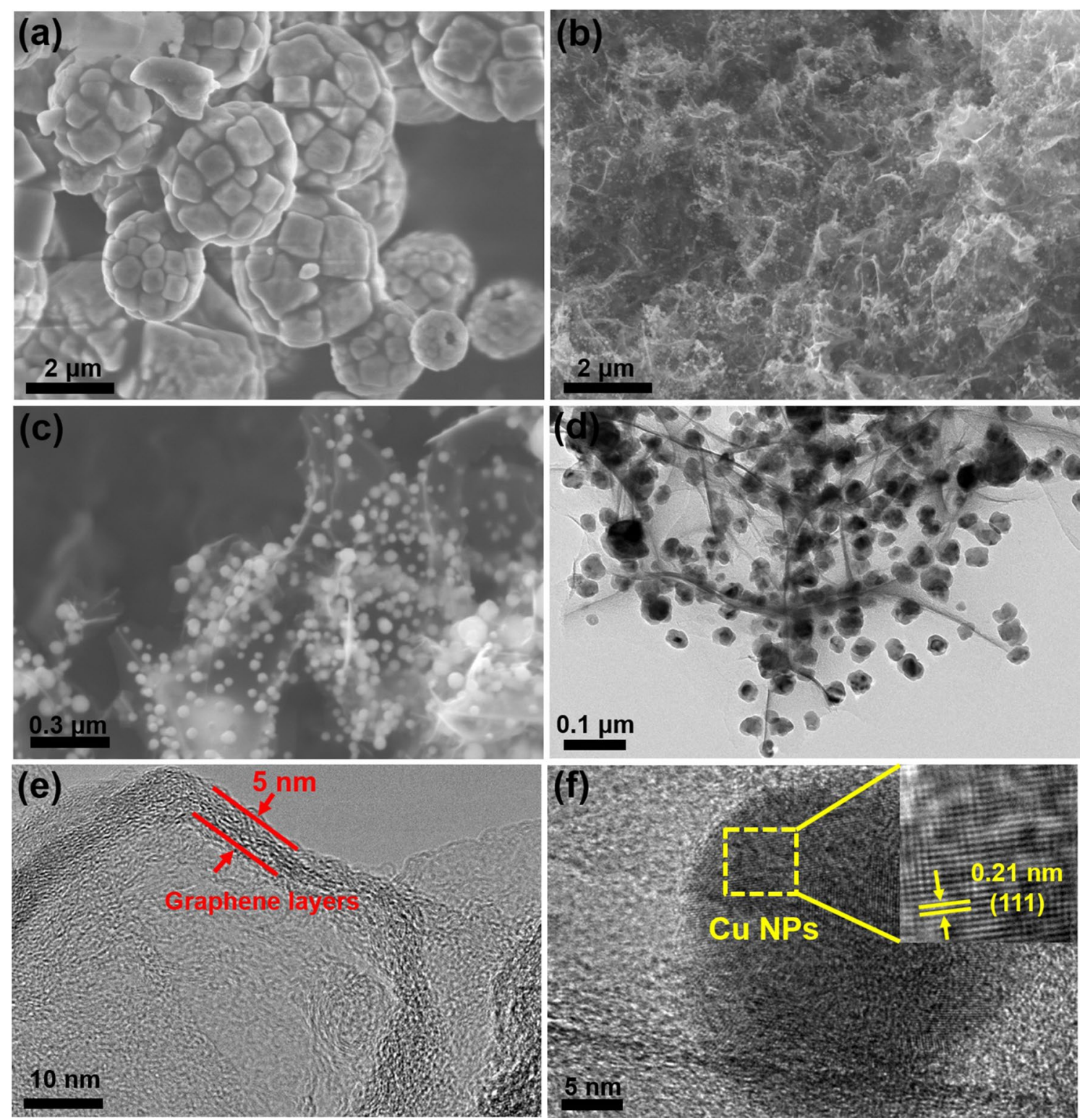

Fig. 2 a SEM image of spherical precursor powder. b, c SEM and high-resolution SEM images of Cu-NPs@GNPs. d TEM image of Cu-NPs distributed on GNPs. High-resolution TEM image of $\mathbf{e}$ graphene layers, $\mathbf{f}$ a typical $\mathrm{Cu}-\mathrm{NP}$

calcining the sample from room temperature to $800{ }^{\circ} \mathrm{C}$ in air. Finally, $\mathrm{Cu}$ and $\mathrm{C}$ were oxidized to $\mathrm{CuO}$ and $\mathrm{CO}_{2}$. According to Fig. 3c, the initial Cu content in Cu-NPs@ GNPs is determined to be $65 \%$ based on the content of $\mathrm{CuO}$ remaining in the final product.

Figure S1 exhibits the SEM images of Cu-NPs, ex situ $\mathrm{Cu}-\mathrm{NPs} / \mathrm{GNPs}$ and pure GNPs. Figure $\mathrm{S} 1 \mathrm{a}$ shows the $\mathrm{Cu}-$ NPs that are impregnated on the surface of $\mathrm{Al}$ powders prepared by impregnation-reduction process. The $\mathrm{Cu}$-NPs with average sizes of about $50 \mathrm{~nm}$ are uniformly dispersed and seldom agglomerated, which can be used as a comparison of $\mathrm{Cu}-\mathrm{NPs}$ coated on the graphene in Cu-NPs@GNPs. Figure $\mathrm{S} 1 \mathrm{~b}$ presents the raw GNPs used to prepare ex situ $\mathrm{Cu}-\mathrm{NPs} /$
GNPs by electroless copper plating method. Figure S1c shows the ex situ Cu-NPs/GNPs prepared by reducing the co-precipitation of GNPs and $\mathrm{Cu}(\mathrm{OH})_{2}$ (the detailed production process is shown in supporting information). As can be seen, the distribution of $\mathrm{Cu}$-NPs on the surface of GNPs is not very uniform. Some $\mathrm{Cu}-\mathrm{NPs}$ tend to agglomerate into larger particles on the GNPs while in some other regions few located. Moreover, the stacking phenomenon between graphene nanoplatelets is serious. As is known, SEM image of ultra-thin graphene nanoplatelets should have low contrast like Cu-NPs@ GNPs in Fig. 2c. Thus, compared with $\mathrm{Cu}$ NPs@GNPs, ex situ Cu-NPs/GNPs are not thin enough and demonstrate more easily to agglomerate. As for coating $\mathrm{Cu}$ 

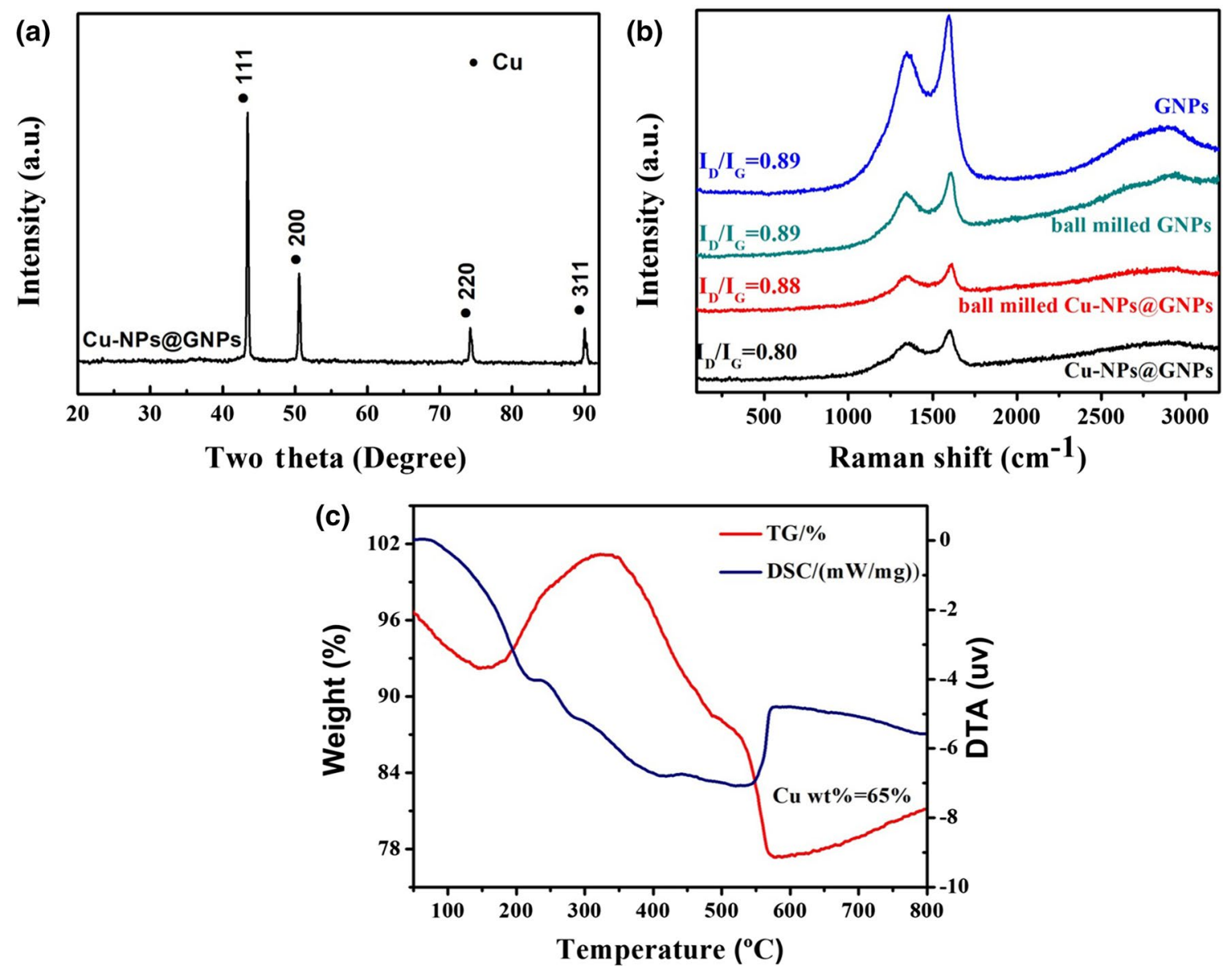

Fig. 3 a XRD pattern of in situ synthesized Cu-NPs@GNPs. b Raman spectrum of in situ synthesized Cu-NPs@GNPs and pure GNPs before and after ball milling process. c TGA and DTA profile of in situ synthesized Cu-NPs@GNPs

nanoparticles on the surface of GNPs, in situ catalyzed synthesis method with the assistance of $\mathrm{NaCl}$ templates is better. Figure S1d presents the SEM image of pure GNPs, which is prepared by etching off $\mathrm{Cu}-\mathrm{NPs}$ from the in situ synthesized Cu-NPs@GNPs. After removing Cu-NPs, the GNPs with ultra-thin thickness still maintain clear frame structures.

\subsection{Dispersion of GNPs in Al Powders During Ball Milling}

Shift-speed ball milling was applied to disperse Cu-NPs@ GNPs into $\mathrm{Al}$ powders. Figure $4 \mathrm{a}$ and $\mathrm{b}$ presents the morphology of Cu-NPs@GNPs/Al powders after LSBM process (180 rpm for $2 \mathrm{~h}$ ). During LSBM process, the shape of Al powders is still nearly spherical without excessive deformation, and Cu-NPs@GNPs is attached to the surface of Al powders. After HSBM (360 rpm for $1.5 \mathrm{~h}$ ) process (Fig. 4b, c), Al powders are flatted under the intense shear force. The Cu-NPs@GNPs are embedded into the Al powders and no obvious wrinkle structures of GNPs are observed on the surface of the flatted Al powders. The simple mixture of
$\mathrm{Cu}-\mathrm{NPs}$, pure GNPs (Cu-NPs@ GNPs removed $\mathrm{Cu}$ ) and $\mathrm{Al}$ powders is carried out with the same shift-speed ball milling process, with its morphology exhibited in Fig. 4e, f. Obvious GNPs agglomerates could be observed. These results indicate that GNPs coated with $\mathrm{Cu}-\mathrm{NPs}$ are more easily to be dispersed in Al powders than pure GNPs via ball milling. This phenomenon could be explained from two aspects: On the one hand, attaching metal nanoparticles on GNPs compromise the density mismatch between GNPs and metal powders, which could improve the dispersion of GNPs in the preparation of composites [27]. On the other hand, metal nanoparticles play the role of a spacer between graphene layers to limit the agglomeration of it [28]. Additionally, the obtained Cu-NP@GNPs/Al and GNPs/Al powders through ball milling process were detected by Raman spectra which revealed the structural damage of Cu-NPs@GNPs and GNPs after the ball milling process. As shown in Fig. $3 \mathrm{~b}$, the $I_{\mathrm{D}} / I_{\mathrm{G}}$ values are 0.88 and 0.89 , respectively. The minimal change of the $I_{\mathrm{D}} / I_{\mathrm{G}}$ values demonstrates that there is almost no damage to the GNPs structure during the shift-speed ball milling process. 

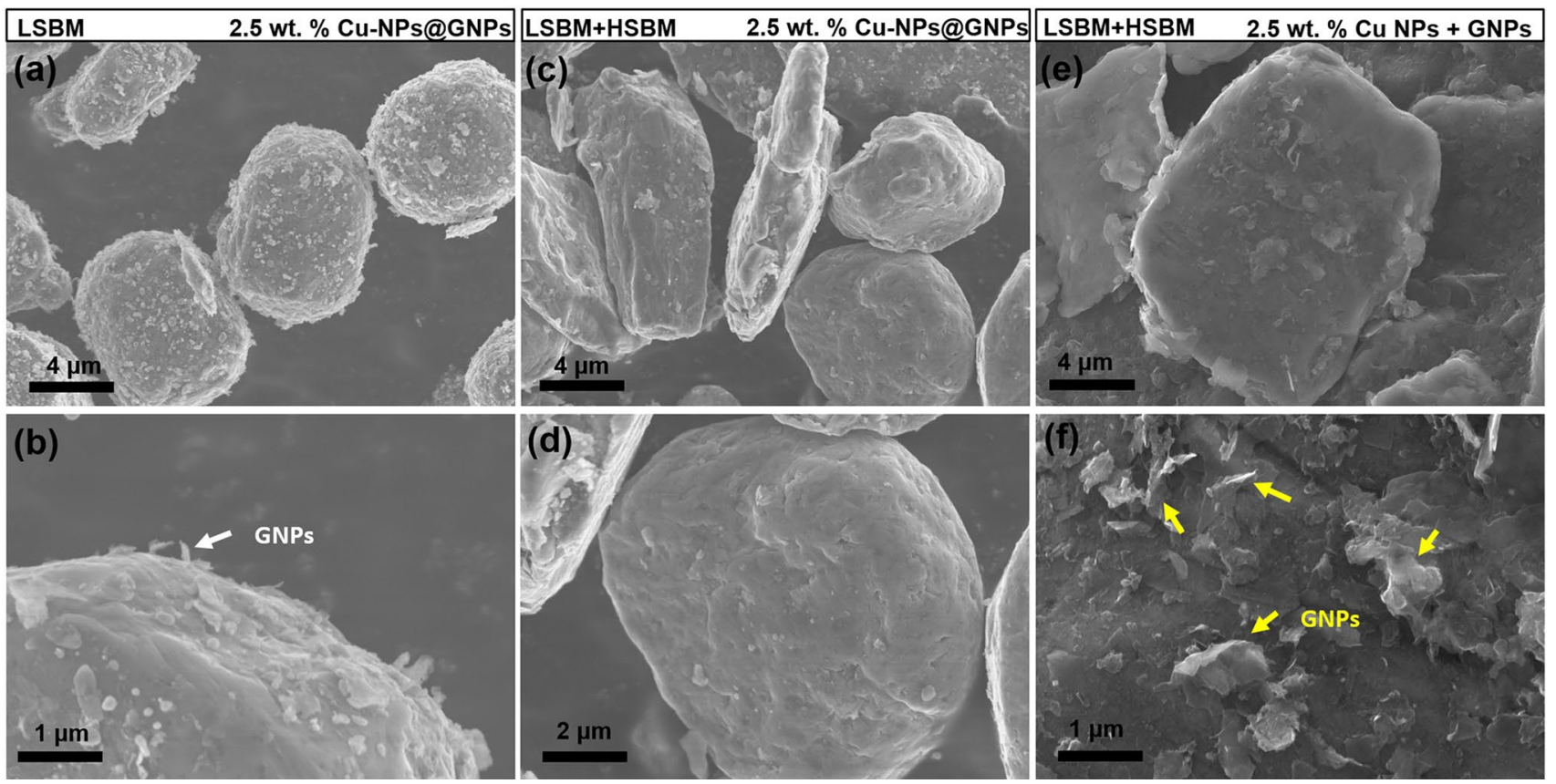

Fig. 4 SEM images of a, b 180 r-120 min ball milled 2.5 wt\% Cu-NPs@ GNPs/Al powders, c, d 180 r-120 min and 360 r-90 min ball milled CuNPs@GNPs/Al powders, e, f 180 r-120 min and 360 r-90 min ball milled mixture of (Cu-NPs + GNPs)/Al powders

\subsection{Microstructures of the Cu-NPs@GNPs/AI Composites}

Figure 5a-c shows the morphologies of $\mathrm{Si}$ in the matrix of Sr-modified Al-10Si, 0.3 and 0.5 wt\% Cu-NPs@GNPs/ Al-10Si composite, and the average size of $\mathrm{Si}$ are $3.86,3.71$ and $3.69 \mu \mathrm{m}$, respectively. From Fig. 5a-c, as the Cu-NPs@ GNPs content increases, the $\mathrm{Si}$ in matrix tends to decrease in size, and the morphology changes from fibrous to spherical. However, due to the refinement effect of Sr modifier, the sizes of silicon in all composites are uniform, which results in an unobvious contrast effect. In order to eliminate (a)

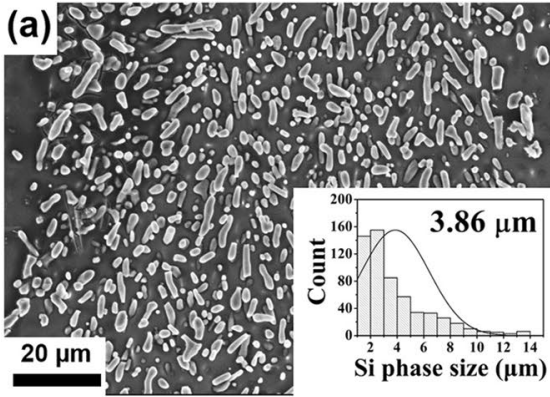

\section{(d)}

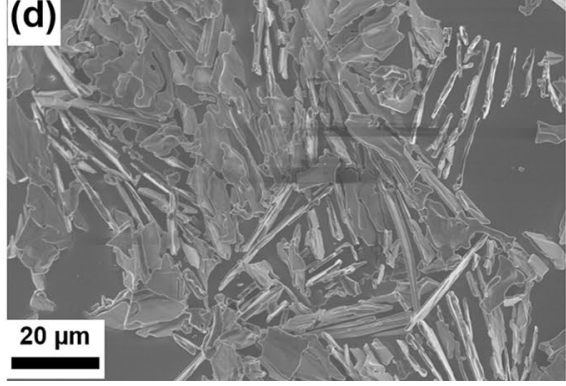

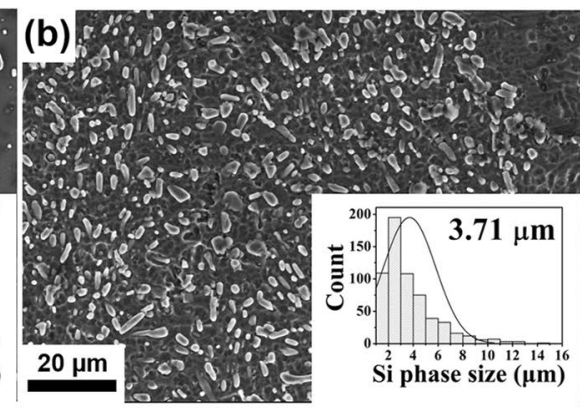

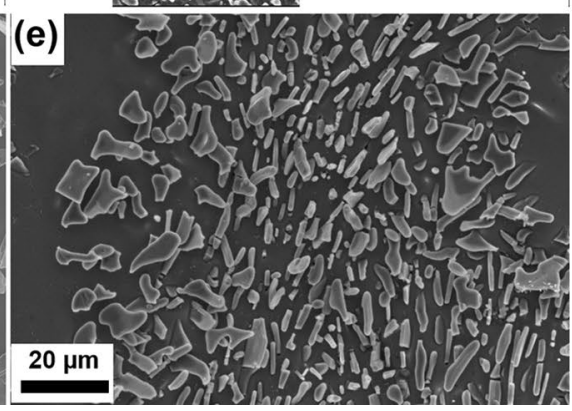

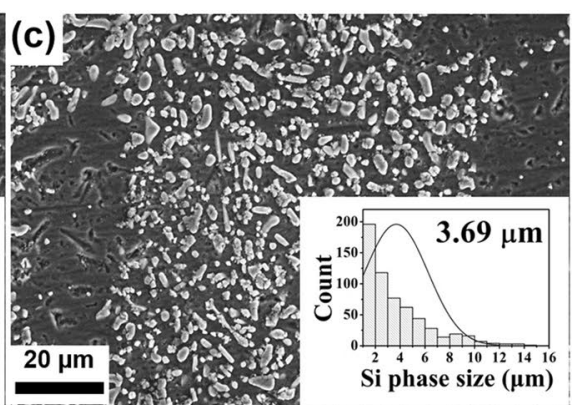

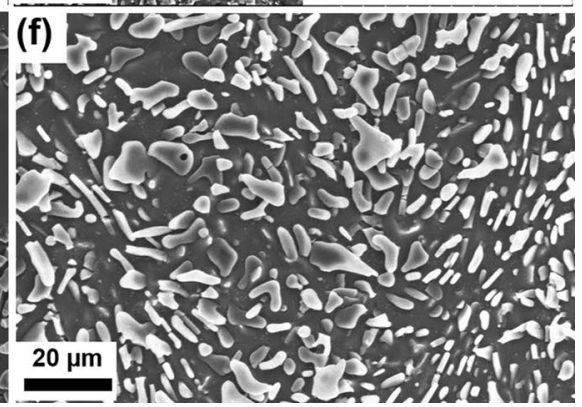

Fig. 5 Si morphologies of Al-10Si and composites reinforced by Cu-NPs@GNPs: a modified Al-10Si, b, c modified 0.3 and 0.5 wt $\%$ Cu-NPs@ GNPs/Al-10Si, d unmodified Al-10Si, e, f unmodified 0.3 and 0.5 wt\% Cu-NPs@ GNPs/Al-10Si 
the interference of Sr, Al-10Si matrix and Cu-NPs@GNPs/ $\mathrm{Al}-10 \mathrm{Si}$ composites were prepared without introduced $\mathrm{Sr}$. The corresponding morphology of $\mathrm{Si}$ is shown in Fig. 5e and f. As can be seen from the images, in unmodified Al-10Si matrix, Si presents a large flake with the length of about $20 \mu \mathrm{m}$. After adding 0.3 wt\% Cu-NPs@GNPs, Si is refined into the smaller flake with the length of about $8 \mu \mathrm{m}$. When the content of Cu-NPs@GNPs increases to 0.5 wt \%, Si phases tend to change from flake to rod. We may attribute that to the Cu-NPs@GNPs in Al-10Si melt provide more nucleation sites for $\mathrm{Si}$ which improves nucleation rate and promoting the refinement of $\mathrm{Si}$. This result indicates that graphene nanoplatelets do have a refining effect on silicon, but when $\mathrm{Sr}$ modifier is used in the matrix, the relatively close silicon sizes make it difficult to distinguish.

To confirm that the refining effect of $\mathrm{Cu}-\mathrm{NPs} @$ GNPs on silicon is derived from $\mathrm{Cu}-\mathrm{NPs}$ or GNPs, the Si morphology of $0.5 \mathrm{wt} \%$ (ex situ Cu-NPs/GNPs)/Al-10Si composite, $0.195 \mathrm{wt} \%$ (Cu-NPs)/Al-10Si composite, and $0.325 \mathrm{wt} \%$ $(\mathrm{Cu}-\mathrm{NPs}) / \mathrm{Al}-10 \mathrm{Si}$ composite is characterized, and the corresponding results are presented in Fig. 6, which shows that the size of silicon decreases with addition of ex situ $\mathrm{Cu}-\mathrm{NPs} /$ GNPs, but tends to grow as $\mathrm{Cu}-\mathrm{NPs}$ content increases. In summary, the reinforcement containing GNPs could refine
$\mathrm{Si}$ while $\mathrm{Cu}-\mathrm{NPs}$ alone make $\mathrm{Si}$ coarsening which indicates that the refinement effect comes from GNPs.

Raman mapping was utilized to detect the trace of GNPs in the 1.0 wt\% Cu-NPs@GNPs composite, with the result displayed in Fig. 7. The 900 detection points are taken from the scanned region of $20 \mu \mathrm{m} \times 20 \mu \mathrm{m}$ marked by the white square in Fig. 7a. Figure $7 \mathrm{~b}$ is Raman spectrum of a point from the map, clearly showing both $\mathrm{D}\left(1357 \mathrm{~cm}^{-1}\right)$ and $\mathrm{G}$ (1605 $\mathrm{cm}^{-1}$ ) bands with the $I_{\mathrm{D}} / I_{\mathrm{G}}$ value of 0.89 , which is consistent with the Raman spectra result of Cu-NPs@GNPs in Fig. 3b. Figure 7c, d displays the intensity variation of D and $\mathrm{G}$ bands during the mapping process, in which blue and yellow area represent the high D-band intensity and high G-band intensity regions, respectively. Thus, the positions where colorful areas of Fig. 7c, d exist simultaneously indicate the presence of GNPs. The results confirm the presence of GNPs with good quality in the composite.

TEM observation of 0.5 wt\% Cu-NPs@GNPs/Al-10Si composites is shown in Fig. 8. In the matrix, two types of GNPs are observed: GNPs attached with (Fig. 8a) and without (Fig. 8b, c) $\mathrm{Al}_{2} \mathrm{Cu}$ nanoparticles on the surface. In addition, $\mathrm{Al}_{2} \mathrm{Cu}$ precipitates are found on the aluminum grain boundary or in the crystal, the sizes of which vary from 20 to $100 \mathrm{~nm}$. Since the maximum solubility of $\mathrm{Cu}$ in $\mathrm{Al}$
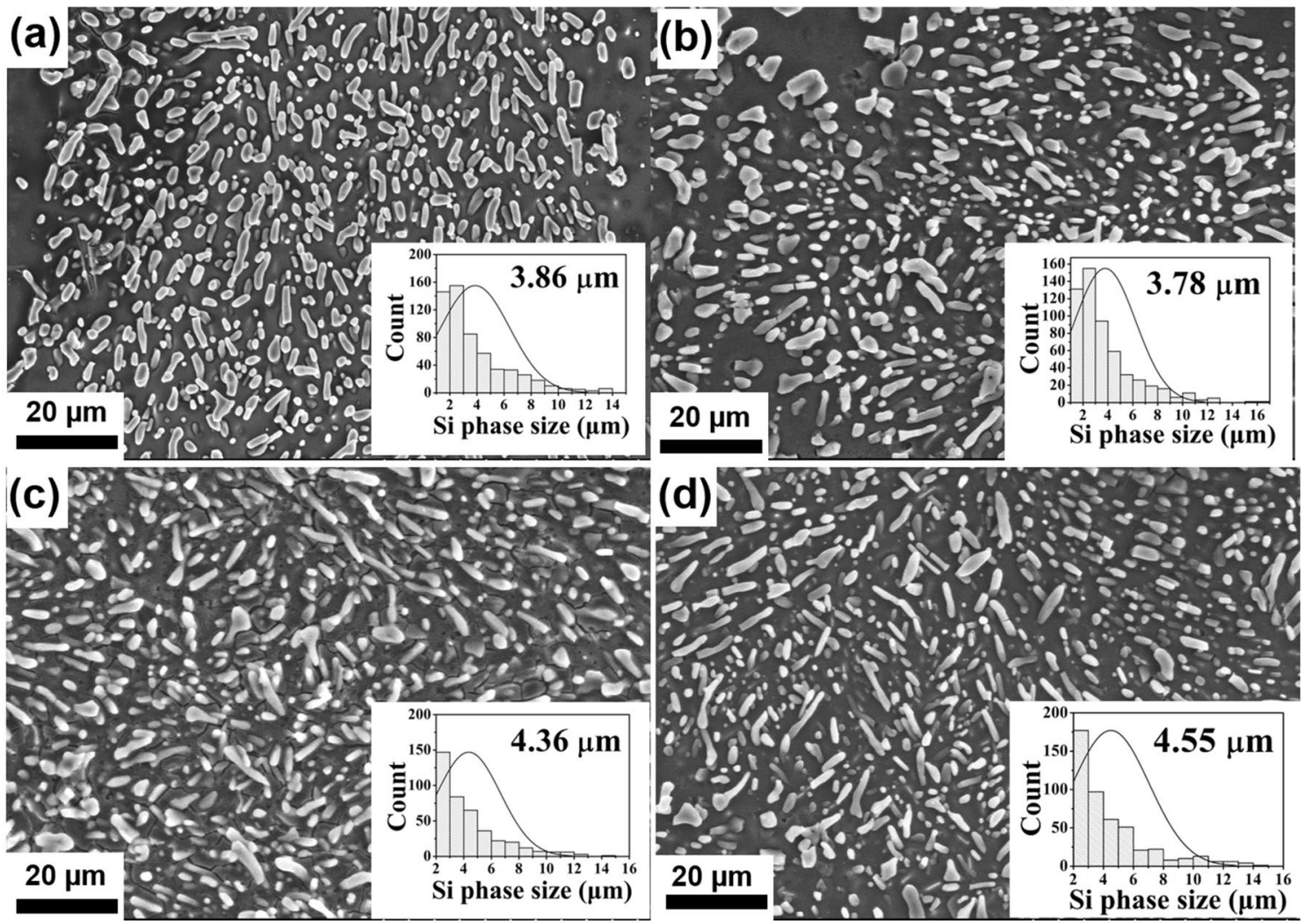

Fig. 6 Si morphologies of a modified Al-10Si, b modified 0.5 wt\% (ex situ Cu-NPs/GNPs)/Al-10Si composite, c modified 0.195 wt\% (Cu$\mathrm{NPs}$ )/Al-10Si composite, $\mathbf{d}$ modified $0.325 \mathrm{wt} \%$ (Cu-NPs)/Al-10Si composite 


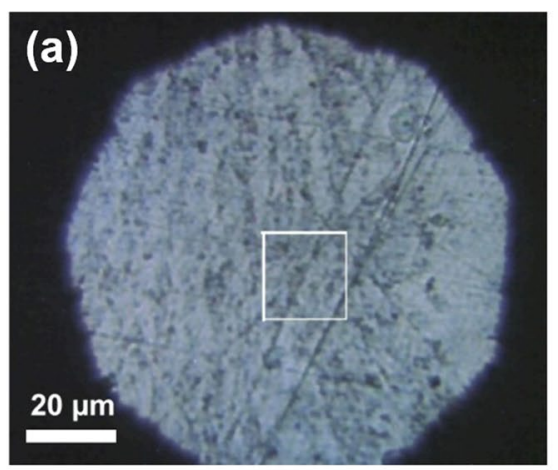

(b)
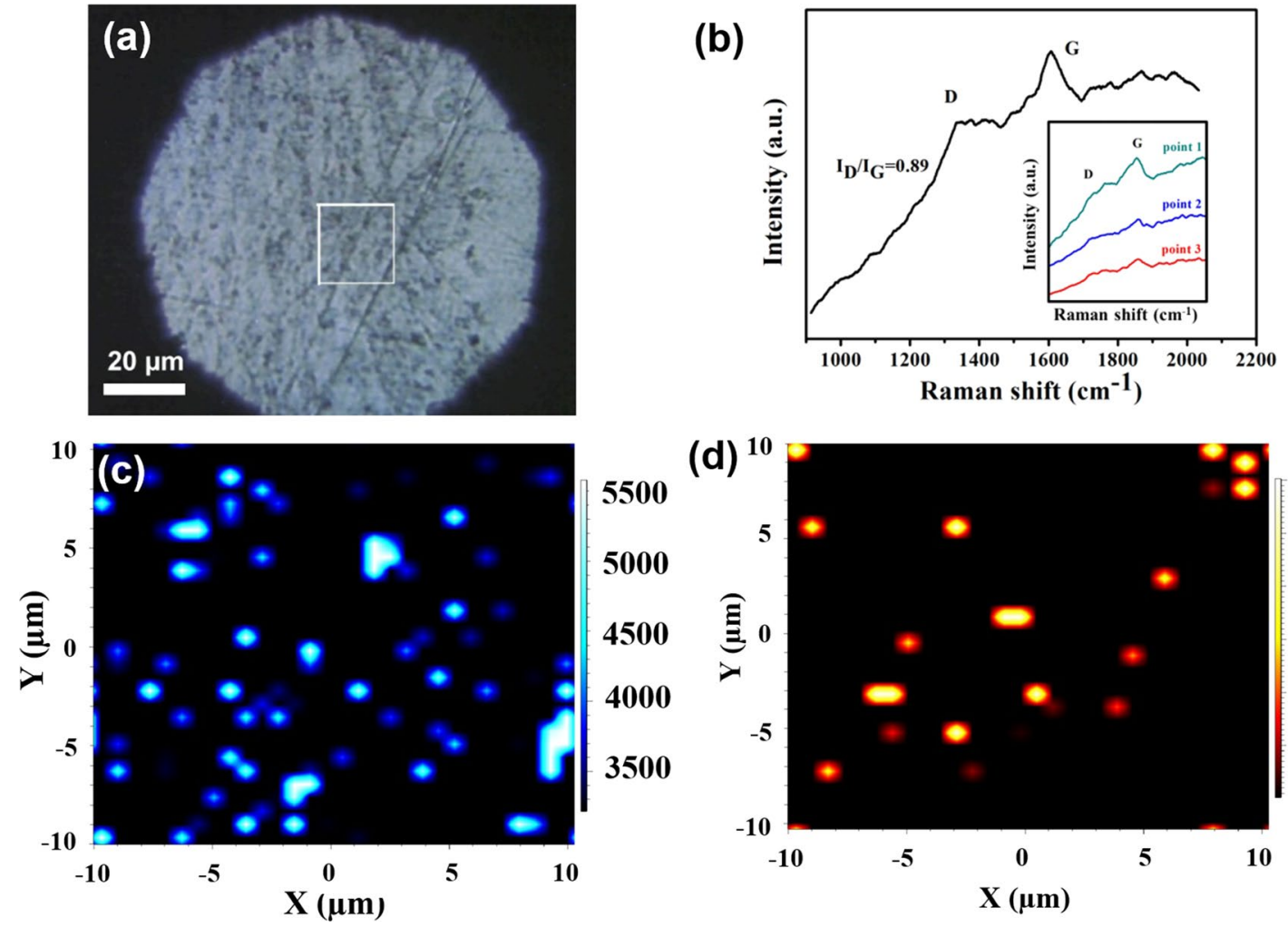

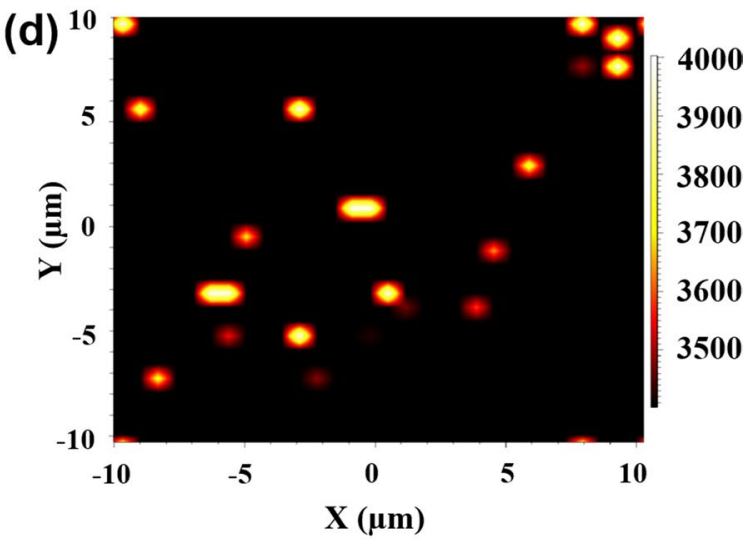

Fig. 7 Raman results of the $1.0 \mathrm{wt} \%$ (Cu-NPs@GNPs)/Al-10Si bulk sample. a Optical image from the sample showing the scanned area of $20 \mu \mathrm{m} \times 20 \mu \mathrm{m}$ outlined by white square. b Raman spectrum of some points from the map. c D-band intensity. d G-band intensity

could reach $5.65 \%$ under $750{ }^{\circ} \mathrm{C}$, during the mechanical stirring process of molten alloy, a part of $\mathrm{Cu}-\mathrm{NPs}$ may detach from the GNPs and dissolves into matrix then react with aluminum forming the intermetallic compound $\mathrm{Al}_{2} \mathrm{Cu}$. The remaining $\mathrm{Cu}-\mathrm{NPs}$ on the surface of GNPs also react with $\mathrm{Al}$ to form $\mathrm{Al}_{2} \mathrm{Cu}$, which not only improves the wettability between $\mathrm{Al}$ and GNPs, but also helps to inhibit the interface reaction between $\mathrm{Al}$ and GNPs to protect the GNPs structure.

It was difficult to distinguish eutectic silicon and aluminum matrix in the TEM image, so EDS was utilized to analyze the distribution and correlation of $\mathrm{Al}, \mathrm{Si}$, and $\mathrm{Cu}$ elements in the matrix. Elements mappings in Fig. 9 show two kinds of distribution states of copper-rich precipitates (proved to be $\mathrm{Al}_{2} \mathrm{Cu}$ ): precipitating in aluminum matrix (Fig. 9a-d) or precipitating at the aluminum-silicon interface (Fig. 9e-h).

\subsection{Mechanical Properties of Composites}

Hot rolling was applied to all the cast composites to refine grains of the composites and eliminate defects of microstructure, thus making the composites compacted and improving mechanical properties. The tensile test curves of the hotrolled Al-10Si and Cu-NPs@GNPs/Al-10Si composites are displayed in Fig. 9a. The result demonstrates that the tensile strength of composites displays an increasing trend with the increase of reinforcement content. Particularly, the Al-10Si with 0.5 wt\% Cu-NPs@GNPs shows a 45\% enhancement in the tensile strength (from 173 to $251 \mathrm{MPa}$ ). When the reinforcement content increases to $1.0 \mathrm{wt} \%$, the tensile strength of the composite decreases from $251 \mathrm{MPa}$ $(0.5 \mathrm{wt} \%)$ to $196 \mathrm{MPa}$, which may be caused by the high content of GNPs tend to self-assemble into clusters. According to the preparation process in this work, $1.0 \mathrm{wt} \% \mathrm{Cu}$ NPs@GNPs composites corresponded to Al-5wt \% (CuNPs@GNPs) master alloy. Thus, Cu-NPs@GNPs of high content tended to aggregate together in both ball milling and melting process.

Figure S2 shows the fracture morphology of composites reinforced by various content of Cu-NPs@GNPs. As can be seen from Figure S2a-f, both Al-10Si and Cu-NPs@GNPs/ Al-10Si composites show a typical micro-void coalescence fracture. In the dimples, the silicon particles and micropores can be observed, while no significant pulling-out of GNPs is found in the composites fracture surfaces (Figure S2c-f). It indicates that when bearing the external force, the composites firstly break from the $\mathrm{Al} / \mathrm{Si}$ bonding interface, rather than from the Al/GNPs interface, which also proves that the Al/GNPs interface combines well. Figure $\mathrm{S} 2 \mathrm{~g}$ shows the 

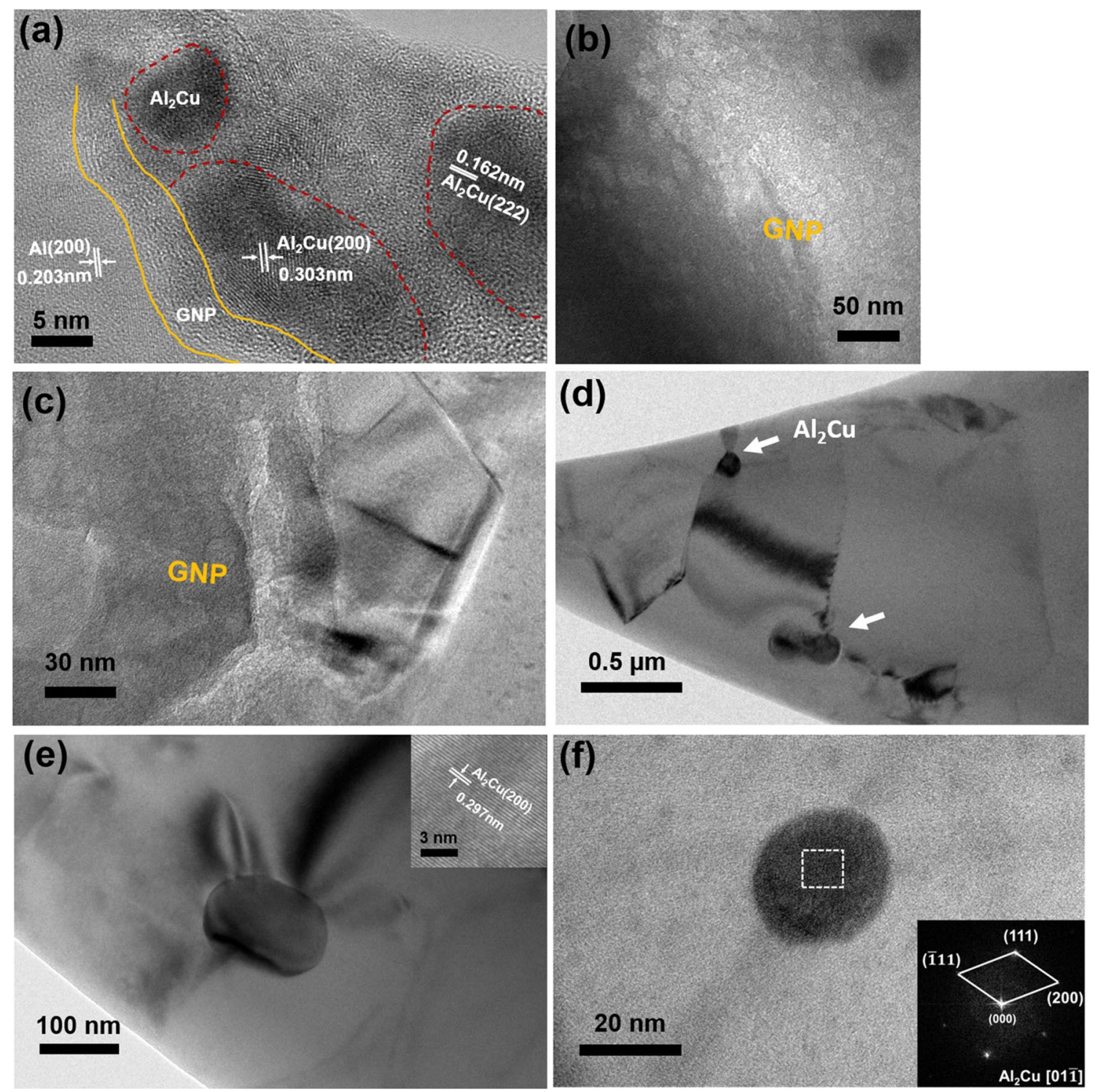

Fig. 8 HRTEM images of microstructure in 0.5 wt $\% \mathrm{Cu}-\mathrm{NPs} @ \mathrm{GNPs} / \mathrm{Al}-10 \mathrm{Si}$ composite: a GNPs and $\mathrm{Al}_{2} \mathrm{Cu}, \mathbf{b}, \mathbf{c} \mathrm{GNPs}, \mathbf{d} \mathrm{Al}_{2} \mathrm{Cu}$ in the aluminum grain boundary, $\mathbf{e}, \mathbf{f ~} \mathrm{Al}_{2} \mathrm{Cu}$ in the aluminum crystal

fracture morphology of $1.0 \mathrm{wt} \% \mathrm{Cu}-\mathrm{NPs} @ \mathrm{GNPs} / \mathrm{Al}-10 \mathrm{Si}$ composite. No Si particles or micropores are observed in the dimples, but some broken inclusions. Pulling-out GNPs are observed in the high-resolution SEM image of the inclusions. The phenomenon is consistent with the tensile test result of 1.0 wt \% Cu-NPs@GNPs composite. Excessive CuNPs@GNPs cannot be uniformly dispersed in the matrix but agglomerates together as defects, resulting in a decrease in mechanical properties of the composite.

Considering the high proportion of $\mathrm{Cu}-\mathrm{NPs}$ in $\mathrm{Cu}-\mathrm{NPs} @$ GNPs reinforcement (i.e., $65 \mathrm{wt} \%$ ), the strengthening effect of $\mathrm{Cu}$-NPs in this composite system cannot be ignored. In order to confirm the actual strengthening effect of GNPs, $\mathrm{Cu}-\mathrm{NPs} / \mathrm{Al}-10 \mathrm{Si}$ composites were also performed tensile test, as a comparison. As shown in Fig. 10b, 0.195 and $0.325 \mathrm{wt} \% \mathrm{Cu}-\mathrm{NPs}$ increase the tensile strength of Al-10Si by $7.5 \%$ and $19.6 \%$, respectively, while the elongations are seriously reduced. Then, according to the strengthening effect of Cu-NPs@GNPs and the proportion of GNPs in it, it can be estimated that $0.105 \mathrm{wt} \%$ and $0.175 \mathrm{wt} \%$ GNPs can increase the tensile strength of composites by $7 \%$ and $25.4 \%$, respectively. In fact, the strengthening of $\mathrm{Cu}-\mathrm{NPs}$ and GNPs of Cu-NPs@GNPs cannot be simply added together, and their synergistically reinforcing effects will be discussed in the next section.

Controlling the addition of $\mathrm{Cu}$ at the same level $(0.325 \mathrm{wt} \%)$, tensile strengths of in situ synthesized $\mathrm{Cu}$ NPs@GNPs, ex situ Cu-NPs/GNPs, simple mixture of 

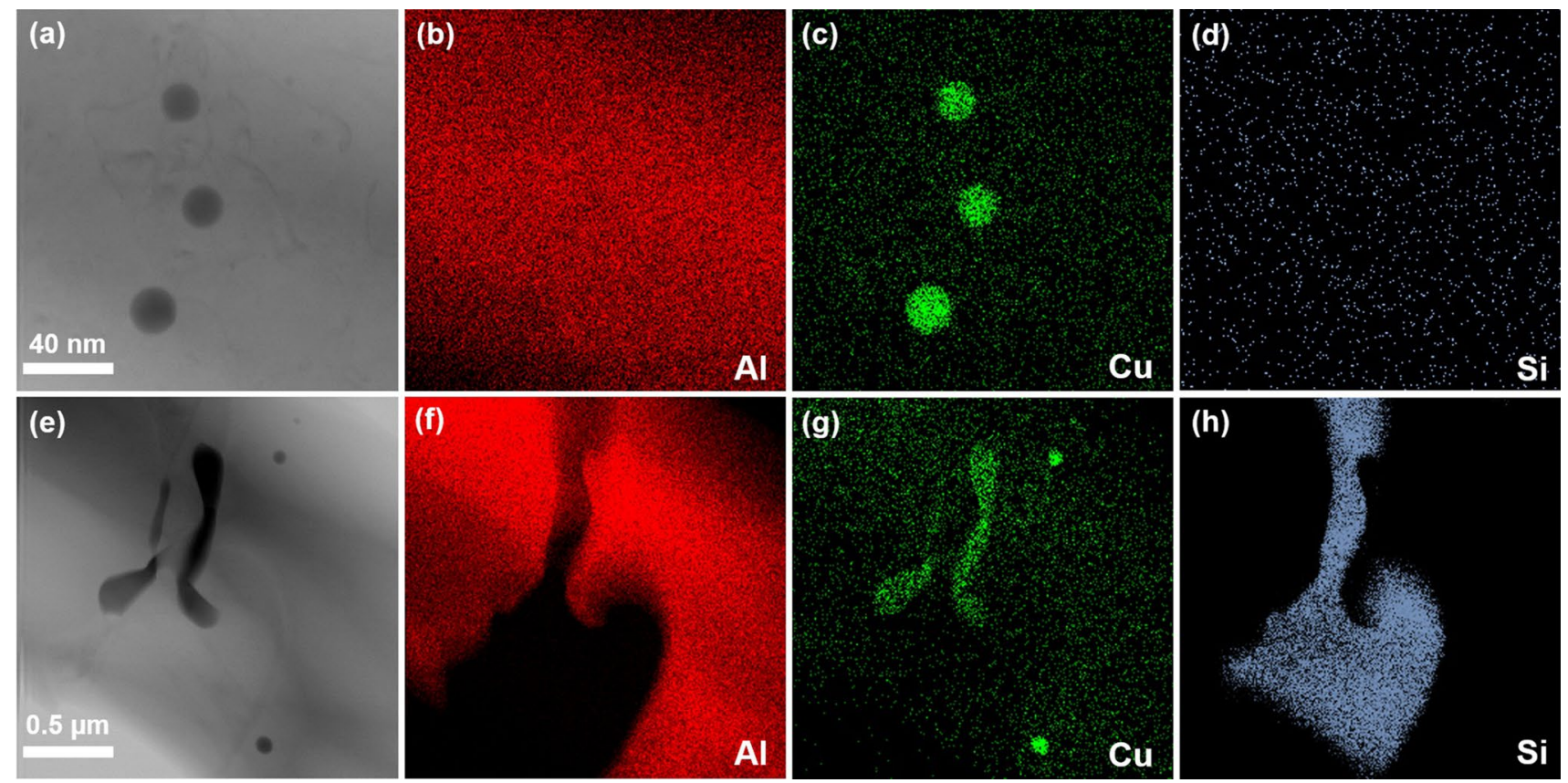

Fig. 9 Elemental mapping images of 0.5 wt\% Cu-NPs@GNPs/Al-10Si: a $\mathrm{Al}_{2} \mathrm{Cu}$ in the aluminum matrix, b-d Al, $\mathrm{Cu}, \mathrm{Si}$ elements distribution in (a), e $\mathrm{Al}_{2} \mathrm{Cu}$ at the $\mathrm{Al}-\mathrm{Si}$ interface, $\mathbf{f}-\mathbf{h} \mathrm{Al}, \mathrm{Cu}, \mathrm{Si}$ elements distribution in (e)

$(\mathrm{Cu}-\mathrm{NPs}+\mathrm{GNPs})$ reinforced composites were compared, and the tensile curves are shown in Fig. 9c. The sample mixture of (Cu-NPs + GNPs) had almost no strengthening effect on the composites. According to the 3.2, the GNPs with etching off $\mathrm{Cu}-\mathrm{NPs}$ did not disperse well between $\mathrm{Al}$ powders but agglomerated together, which resulted in that the obtained Al-GNPs master alloy was difficult to melt in the subsequent smelting process, thus only a small amount of GNPs was introduced and dispersed in the matrix. The strengthening effect of ex situ Cu-NPs/GNPs is not as effective as Cu-NPs@GNPs, which could be attributed to the agglomeration of GNPs. During the preparation of ex situ $\mathrm{Cu}-\mathrm{NPs} / \mathrm{GNPs}$, the electroless copper plating method was used to coat $\mathrm{Cu}$ particles on the graphene nanoplatelets but it was difficult to ensure sufficient space distribution of $\mathrm{Cu}$ NPs between GNPs layers. The GNPs without enough $\mathrm{Cu}-$ NPs attached tended to be tightly bonded or even stacked. Therefore, it was difficult for ex situ Cu-NPs/GNPs to be uniformly dispersed in the matrix and exert strengthening effect during the preparation of composites.

\section{Discussion}

\subsection{Effect of Cu-NPs@GNPs on Silicon Phases}

Above results indicate that GNPs have the refining effect on $\mathrm{Si}$ while $\mathrm{Cu}-\mathrm{NPs}$ make Si coarsening when it was added into Al-10Si alloy. The details will be discussed.
Regarding the influence of the addition of $\mathrm{Cu}$ on the silicon phase, previous literature has given various opinions on this: Mørtsell et al. [29] found that the addition of $1.0 \mathrm{wt} \%$ $\mathrm{Cu}$ into A356 alloy decreased the Si size. The phenomenon was explained with quenching vacancies: $\mathrm{Cu}$ and $\mathrm{Si}$ both have a high affinity for vacancies, and the addition of a solute with high affinity for vacancies $(\mathrm{Cu})$ in the matrix contributes to the precipitation of the silicon phase. Seifeddine et al. [30] reported that the addition of $0-0.5 \mathrm{wt} \% \mathrm{Cu}$ to the A365 alloy coarsened the silicon phase. In addition, other study [31] reported that, in Sr-containing alloys, the addition of $\mathrm{Mg}$ or $\mathrm{Cu}$ decreased the modifying effect of $\mathrm{Sr}$ by reacting with $\mathrm{Si}$ and $\mathrm{Sr}$ to form $\mathrm{Mg}_{2} \mathrm{Sr}-\left(\mathrm{Si}_{3} \mathrm{Al}_{4}\right)$ and $\mathrm{Al}-\mathrm{Cu}-\mathrm{Sr}$ compounds, which finally resulted in the increase of silicon phase size.

In this study, $\mathrm{Al}_{2} \mathrm{Cu}$ is observed to precipitate at the $\mathrm{Al} /$ $\mathrm{Si}$ interface. There was no trace of $\mathrm{Al}-\mathrm{Cu}-\mathrm{Sr}$ compounds observed in the composite matrix. The effect of $\mathrm{Cu}$ is attributed to the interface energy: The precipitation of $\mathrm{Al}_{2} \mathrm{Cu}$ at $\mathrm{Al} / \mathrm{Si}$ interface consumes the nucleation driving energy of $\mathrm{Si}$, which prevents the $\mathrm{Si}$ from further nucleating. As a result, the silicon phase gradually coarsens as the $\mathrm{Cu}$ content increases.

Previous studies have demonstrated that the introduction of reinforcement such as $\mathrm{SiC}$ [32], $\mathrm{TiB}_{2}$ [33], $\mathrm{Al}_{2} \mathrm{O}_{3}$ [34] into $\mathrm{Al}-\mathrm{Si}$ alloys can effectively refine the silicon phase by providing heterogeneous nucleation. The refinement of GNPs to silicon was also been observed by Yang et al. [35]. They found that the addition of $1.5 \mathrm{wt} \%$ graphene nanoflakes 

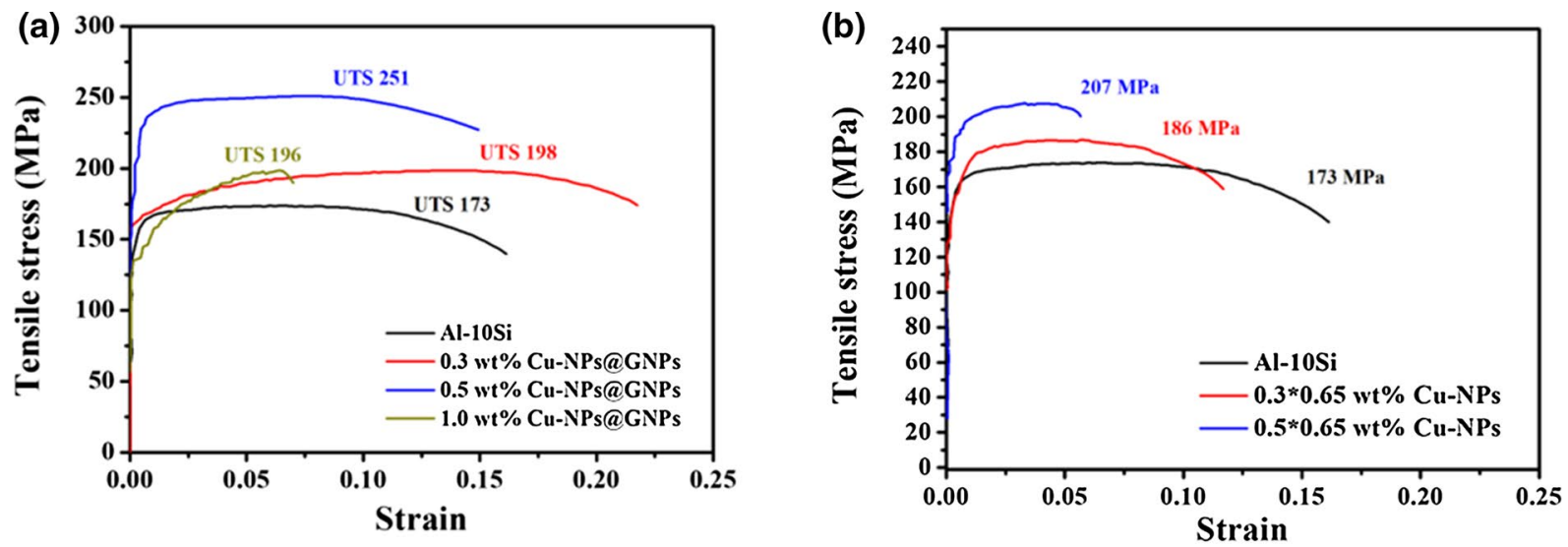

(c)
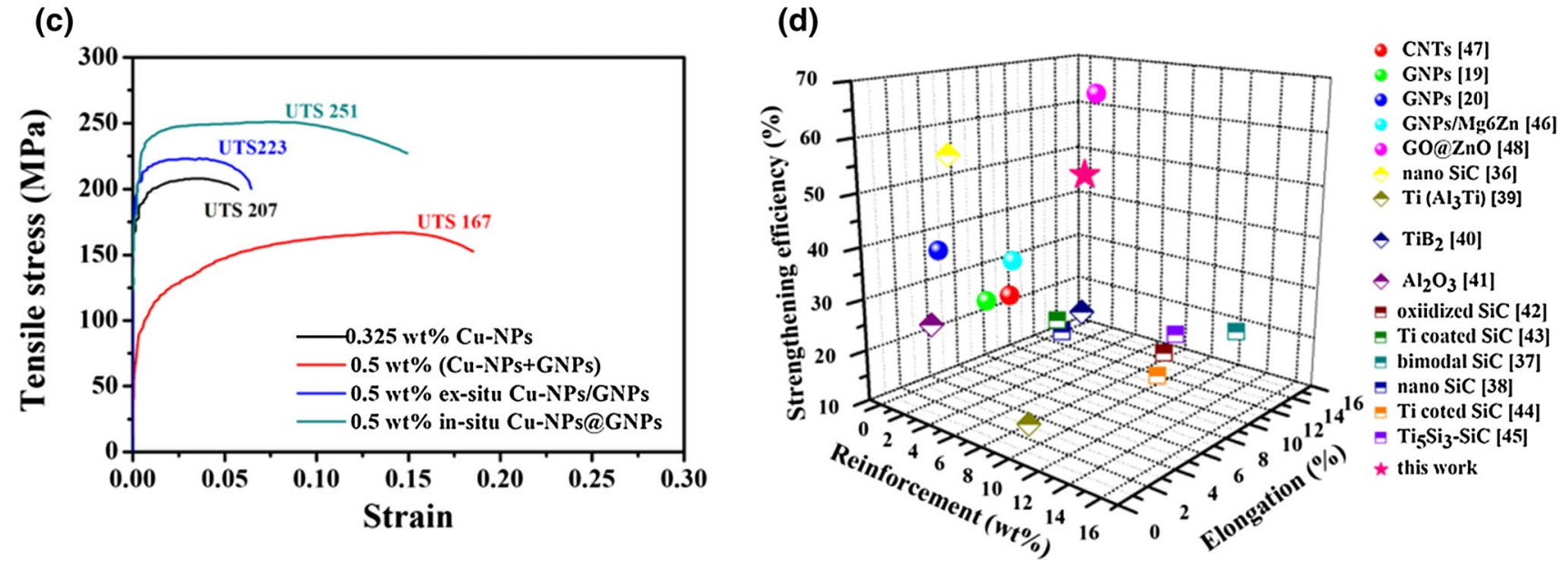

Fig. 10 Stress-strain curves of a Al-10Si and composites reinforced by various content of Cu-NPs@GNPs, b Al-10Si and composites reinforced by various content of $\mathrm{Cu}-\mathrm{NPs}$, c composites reinforced by $\mathrm{Cu}-\mathrm{NPs}$, mixture of $\mathrm{Cu}-\mathrm{NPs}$ and GNPs, ex situ Cu-NPs/GNPs and in situ synthesized Cu-NPs@GNPs. d Comparison of strengthening efficiency and total elongation related to reinforcement contents of metal composites reinforced by different types of reinforcement fabricated by stir casting method

into $\mathrm{Al}-20 \mathrm{Si}$ matrix refined the primary Si from $46 \mu \mathrm{m}$ to $7.6 \mu \mathrm{m}$. When the graphene with a large surface area was added into $\mathrm{Al}-\mathrm{Si}$ alloy melt, it can provide many nucleation sites for $\mathrm{Si}$ and improve the nucleation rate of silicon, thereby the silicon phase was refined. In conclusion, the comparative results demonstrate that although the introduction of $\mathrm{Cu}$ into $\mathrm{Al}-\mathrm{Si}$ alloy would coarsen silicon phase, the Cu-NPs@GNPs synthesized in this work still has refinement effect on the silicon phase, in which GNPs play a key role in refining silicon phase.

\subsection{Strengthening Mechanisms}

As shown in Fig. 10d, references chosen to compare with this study are metal matrix composites fabricated by stir casting method. The conventional reinforcement, such as $\mathrm{SiC}$ [36-38], $\mathrm{Ti}\left(\mathrm{Al}_{3} \mathrm{Ti}\right)$ [39], $\mathrm{TiB}_{2}$ [40], $\mathrm{Al}_{2} \mathrm{O}_{3}$ [41], are added in large quantities, which easily damage the elongation of composites due to agglomeration or poor interfacial bonding. Surface modification [42-45] can effectively improve the wettability and interfacial bonding, thus enhancing the strength and elongation. On the basis of surface modification, compared with the aforementioned conventional reinforcement, in situ Cu-NPs@GNPs synthesized in this work still shows much better comprehensive strengthening efficiency: the introduction of a small amount of graphene can achieve a good performance improvement, which accords with the development trend of composites as "light weight and high strength". Compared with adding pure carbon nanotubes or graphene [19, 20, 46, 47], the Cu-NPs@ GNPs used in this work not only has advantages in enhancing efficiency on tensile strength, but also maintains a high elongation due to the good dispersion and good wettability of $\mathrm{Al}$ matrix with GNPs coated by $\mathrm{Cu}$. Therefore, the surface modification of the reinforcement is an effective optimization method for the preparation of composite materials by stirring casting. Compared with the post-process modification method of graphene [48], in this work, Cu coating and GNPs catalyzed synthesis are achieved in one-step in situ catalytic process. The method has the advantages of 
simple process, low cost, and large output, which can meet the production demand of graphene for stir casting process and provides an effective way for large-scale preparation of graphene-reinforced aluminum matrix composites.

In this system, the strengthening effect primarily comes from three aspects: Firstly, $\mathrm{Al}_{2} \mathrm{Cu}$ anchored on the GNPs improves the wettability and interfacial bonding between GNPs and the matrix, which enhances the load-transfer effect of GNPs. Secondly, $\mathrm{Al}_{2} \mathrm{Cu}$ nanoparticles precipitates in the $\mathrm{Al}$ matrix and play a strengthening role. Thirdly, the GNPs refine the silicon phase, which contributes to enhance mechanical properties of the matrix.

In the in situ synthesized Cu-NPs@GNPs system, CuNPs anchored on the GNPs not only compromise the density mismatch and prevent the GNPs from upward floating during the stirring process, but also prevent the GNPs from agglomerating together, so that there can be some gaps between the sheets to let the molten aluminum alloy immerge, which also contributes to interfacial bonding between GNPs and the matrix. In addition, the coated $\mathrm{Cu}$ on the surface of GNPs can inhibit the Al/GNPs interfacial reaction [49] and protect the structure of GNPs in the stirring process. Previous study [50] has shown that the addition of $\mathrm{Cu}$ reduces the activity coefficient of $\mathrm{Al}$ in the melt, thus inhibiting the $\mathrm{Al} / \mathrm{SiC}$ interfacial reaction. In particular, the inhibition effect is better when elements can enrich at the interface. In this work, $\mathrm{Cu}$-coated GNPs were added to the melt as the reinforcement. The $\mathrm{Cu}$ that enriched at the Al/GNPs interface reacts with $\mathrm{Al}$ to form $\mathrm{Al}_{2} \mathrm{Cu}$, resulting in the lack of reactants in the Al/GNPs reaction, which effectively inhibited the latter reaction process and protect the GNPs. It was reported that the reaction between nanoparticles decorated graphene oxide and the metal matrix could provide the driving force for interfacial wettability [48]. Finally, nanoparticles can act as attachment points to improve the bonding between GNPs and matrix [51]. During the bearing process, stress could be efficiently loaded transfer to the GNPs by in situ reaction products $\mathrm{Al}_{2} \mathrm{Cu}$ anchored on the GNPs.

There is no common interface crystallographic orientation between $\mathrm{Al}_{2} \mathrm{Cu}$ and $\mathrm{Si}$ at the $\mathrm{Al} / \mathrm{Si}$ interface, which weaken the bonding between the $\mathrm{Al} / \mathrm{Si}$ interface, and the material always tends to break here. Large amount of $\mathrm{Al}_{2} \mathrm{Cu}$ precipitation in the $\mathrm{Al} / \mathrm{Si}$ interface will seriously deteriorate the elongation of materials. When $\mathrm{Cu}$ in the form of $\mathrm{Cu}$-NPs@GNPs is added to the melt, part of the $\mathrm{Cu}$ is fixed on the $\mathrm{Al} / \mathrm{GNPs}$ interface to form $\mathrm{Al}_{2} \mathrm{Cu}$, which reduces the precipitation of $\mathrm{Al}_{2} \mathrm{Cu}$ on the $\mathrm{Al} / \mathrm{Si}$ interface from the source. This is the reason why the elongation of $\mathrm{Cu}-\mathrm{NPs} @$ GNPs/Al-10Si does not decrease as much as that of $\mathrm{Cu}$ NPs/ Al-10Si. As a result, the best performance is achieved when copper enriches at the Al/GNPs interface.

In the aluminum-silicon alloy system, the refinement of the silicon phase could improve the overall performance of the material. Moreover, the finer the silicon phases, the better the overall performance. In the previous study [52], the silicon phase in both the Sr-modified and Na-modified $\mathrm{Al}-\mathrm{Si}$ alloys were fibrous, but due to the finer size, the tensile strength of the Sr-modified sample was higher than that of the Na modified. Therefore, in this study, besides the load-transfer effect of GNPs, its refinement on the silicon phase also contributes to the improvement of mechanical properties.

Part of the copper introduced by the Cu-NPs@GNPs is dispersed into the matrix forming $\mathrm{Al}_{2} \mathrm{Cu}$. These nanoparticles hinder dislocation motion and produce precipitation strengthening effect, thereby the mechanical properties of composites were improved.

\section{Conclusion}

In summary, the (Cu-NPs@GNPs)/Al-10Si composites are successfully fabricated by stir-casting assisted with hot rolling. The tensile strength of the composite shows a $45 \%$ enhancement from 173 to $251 \mathrm{MPa}$ with 0.5 wt\% Cu-NPs@ GNPs content while the total elongation is $15 \%$. Cu-NPs coated on the GNPs can react with molten $\mathrm{Al}$ to form $\mathrm{Al}_{2} \mathrm{Cu}$, thereby improving the interfacial wettability and interfacial bonding. Load transfer of GNPs, size refinement of silicon phase and precipitation strengthening of $\mathrm{Al}_{2} \mathrm{Cu}$ contribute to the enhancement of the mechanical properties of composites.

Acknowledgements This work was financially supported by the National Natural Science Foundation of China (Grant Nos. 51771130, 51531004, and 51422104), the Tianjin youth talent support program, the Tianjin Natural Science Funds for Distinguished Young Scholars (Grant No. 17JCJQJC44300) and the Tianjin Science and Technology Support Project (Grant No. 17ZXCLGX00060).

\section{References}

[1] S.C. Tjong, Mater. Sci. Eng. R 74, 281 (2013)

[2] S. Amirkhanlou, S. Ji, Crit. Rev. Solid State Mater. Sci. 45, 1 (2019)

[3] C. Lee, X. Wei, J.W. Kysar, J. Hone, Science 321, 385 (2008)

[4] M.D. Stoller, S. Park, Y. Zhu, J. An, R.S. Ruoff, Nano Lett. 8, 3498 (2008)

[5] A.A. Balandin, S. Ghosh, W. Bao, I. Calizo, D. Teweldebrhan, F. Miao, C.N. Lau, Nano Lett. 8, 902 (2008)

[6] K.I. Bolotin, K.J. Sikes, Z. Jiang, M. Klima, G. Fudenberg, J. Hone, P. Kim, H.L. Stormer, Solid State Commun. 146, 351 (2008)

[7] S.E. Shin, H.J. Choi, J.H. Shin, D.H. Bae, Carbon 82, 143 (2015)

[8] M. Bastwros, G.Y. Kim, C. Zhu, K. Zhang, S. Wang, X. Tang, X. Wang, Compos. B Eng. 60, 111 (2014)

[9] Y.Y. Jiang, Z.Q. Tan, R. Xu, G.L. Fan, D.B. Xiong, Q. Guo, Y.S. Su, Z.Q. Li, D. Zhang, Compos. A Appl. Sci. Manuf. 111, 73 (2018)

[10] Z.H. Yu, W.S. Yang, C. Zhou, N.B. Zhang, Z.L. Chao, H. Liu, Y.F. Cao, Y. Sun, P.Z. Shao, G.H. Wu, Carbon 141, 25 (2019) 
[11] H.P. Zhang, X. Cong, W.L. Xiao, K. Ameyama, C.L. Ma, Mater. Sci. Eng. A 658, 8 (2016)

[12] R. Xu, Z.Q. Tan, D.B. Xiong, G.L. Fan, Q. Guo, J. Zhang, Y.S. Su, Z.Q. Li, D. Zhang, Compos. A Appl. Sci. Manuf. 96, 57 (2017)

[13] H. Kwon, J. Mondal, K.A. Alogab, V. Sammelselg, M. Takamichi, A. Kawaski, M. Leparoux, J. Alloys Compd. 698, 807 (2017)

[14] A. Bisht, M. Srivastava, R.M. Kumar, I. Lahiri, D. Lahiri, Mater. Sci. Eng. A 695, 20 (2017)

[15] Z.W. Zhang, Z.Y. Liu, B.L. Xiao, D.R. Ni, Z.Y. Ma, Carbon 135, $215(2018)$

[16] P.Z. Shao, W.S. Yang, Z. Qiang, Q.Y. Meng, T. Xin, Z.Y. Xiu, Q. Jing, Z.H. Yu, G.H. Wu, Compos. A Appl. Sci. Manuf. 109, 151 (2018)

[17] Q. Gao, S.S. Wu, S.L. Lü, X.C. Duan, P. An, Mater. Des. 94, 79 (2016)

[18] H.M. Wang, G.R. Li, Y.T. Zhao, G. Chen, Mater. Sci. Eng. A 527, $2881(2010)$

[19] M. Alipour, R. Eslami-Farsani, Mater. Sci. Eng. A 706, 71 (2017)

[20] M. Li, H.Y. Gao, J.M. Liang, S.W. Gu, W.R. You, D. Shu, J. Wang, B.D. Sun, Mater. Charact. 140, 172 (2018)

[21] G. Liu, N.Q. Zhao, C.S. Shi, E.Z. Liu, F. He, L.Y. Ma, Q. Li, J.J. Li, C.N. He, Mater. Sci. Eng. A 699, 185 (2017)

[22] J. Wang, X. Zhang, N.Q. Zhao, C.N. He, J. Mater. Sci. 54, 5498 (2018)

[23] J. Qin, T.S. Wang, D.Y. Liu, E.Z. Liu, N.Q. Zhao, C.S. Shi, F. He, L.Y. Ma, C.N. He, Adv. Mater. 30, 1704670 (2018)

[24] A.C. Crowther, A. Ghassaei, N. Jung, L.E. Brus, ACS Nano 6, 1865 (2012)

[25] M.R. Ammar, N. Galy, J.N. Rouzaud, N. Toulhoat, C.E. Vaudey, P. Simon, N. Moncoffre, Carbon 95, 364 (2015)

[26] B. Li, L. Zhou, D. Wu, H.L. Peng, K. Yan, Y. Zhou, Z.F. Liu, ACS Nano 5, 5957 (2011)

[27] L.Q. Wu, R.Z. Wu, L.G. Hou, J.H. Zhang, M.L. Zhang, J. Alloys Compd. 750, 530 (2018)

[28] R. Pasricha, S. Gupta, A.K. Srivastava, Small 5, 2253 (2009)

[29] E.A. Mørtsell, F. Qian, C.D. Marioara, Y. Li, J. Alloys Compd. 785, 1106 (2019)

[30] S. Seifeddine, E. Sjölander, T. Bogdanoff, Mater. Sci. Appl. 04, 171 (2013)

[31] M.A. Moustafa, F.H. Samuel, H.W. Doty, S. Valtierra, Int. J. Cast Met. Res. 14, 235 (2002)
[32] S. Nagarajan, B. Dutta, M.K. Surappa, Compos. Sci. Technol. 59, 897 (1999)

[33] H. Gang, W.Z. Zhang, G.H. Zhang, Z.J. Feng, Y.J. Wang, Mater. Sci. Eng. A 633, 161 (2015)

[34] Q.L. Li, T.D. Xia, Y.F. Lan, W.J. Zhao, F. Lu, P.F. Li, J. Alloys Compd. 577, 232 (2013)

[35] W.S. Yang, G.Q. Chen, J. Qiao, S.F. Liu, R. Xiao, R.H. Dong, M. Hussain, G.H. Wu, Mater. Sci. Eng. A 700, 351 (2017)

[36] K. Amouri, S. Kazemi, A. Momeni, M. Kazazi, Mater. Sci. Eng. A 674, 569 (2016)

[37] L.J. Zhang, F. Qiu, J.G. Wang, H.Y. Wang, Q.C. Jiang, Mater. Sci. Eng. A 637, 70 (2015)

[38] L. Wang, F. Qiu, Q. Zou, D.L. Yang, J. Tang, Y.Y. Gao, Q. Li, X. Han, S.L. Shu, F. Chang, Q.C. Jiang, Mater. Charact. 131, 195 (2017)

[39] C. Gang, X.G. Song, H. Nan, H. Wang, Y.F. Tian, J. Alloys Compd. 694, 539 (2017)

[40] Y. Pazhouhanfar, B. Eghbali, Mater. Sci. Eng. A 710, 172 (2018)

[41] S.A. Sajjadi, H.R. Ezatpour, M.T. Parizi, Mater. Des. 34, 106 (2012)

[42] L.J. Zhang, D.L. Yang, F. Qiu, J.G. Wang, Q.C. Jiang, Mater. Sci. Eng. A 624, 102 (2015)

[43] D.L. Yang, F. Qiu, W.X. Zhao, P. Shen, H.Y. Wang, Q.C. Jiang, Mater. Des. 87, 1100 (2015)

[44] Y.Y. Gao, F. Qiu, R. Geng, W.X. Zhao, D.L. Yang, R. Zuo, B.X. Dong, X. Han, Q.C. Jiang, Mater. Charact. 141, 156 (2018)

[45] D.L. Yang, F. Qiu, Q.L. Zhao, Q.C. Jiang, Mater. Sci. Eng. A 688, 459 (2017)

[46] S.L. Xiang, X.J. Wang, M. Gupta, K. Wu, X.S. Hu, M.Y. Zheng, Sci. Rep. 6, 38824 (2016)

[47] J.G. Park, D.H. Keum, Y.H. Lee, Carbon 95, 690 (2015)

[48] M. Wang, Y. Zhao, L.D. Wang, Y.P. Zhu, X.J. Wang, J. Sheng, Z.Y. Yang, H.L. Shi, Z.D. Shi, W.D. Fei, Carbon 139, 954 (2018)

[49] T.L. Han, J.J. Li, N.Q. Zhao, C.N. He, Carbon 159, 311 (2020)

[50] H.T. Tong, F. Qiu, R. Zuo, P. Shen, X.S. Cong, J.S. Liu, H.Y. Yang, Q.C. Jiang, Appl. Surf. Sci. 501, 144265 (2020)

[51] M.X. Li, H.W. Che, X.Y. Liu, S.X. Liang, H.L. Xie, J. Mater. Sci. 49, 3725 (2014)

[52] N. Fatahalla, M. Hafiz, M. Abdulkhalek, J. Mater. Sci. 34, 3555 (1999) 